\title{
Study Subject
}

National Cancer Institute

\section{Source}

National Cancer Institute. Study Subject. NCI Thesaurus. Code C41189.

A matter or an individual that is observed, analyzed, examined, investigated, experimented upon, or/and treated in the course of a particular study. 